\title{
PSYCHE.
}

\section{NOTES ON THE LARVAE OF SOME TEXAN DIPTERA.*}

\author{
BY CHARLES THOMAS BRUES, AUSTIN, TEX.
}

During the past winter I obtained the light yellow silken nest of a spider, which instead of the usual quota of eggs or young spiders, contained a mass of small yellow hymenopterous cocoons and a number of white grubs of various sizes which I supposed to be the larvae of the hymenopteron. Some of the latter soon pupated however, and later emerged, when they proved to belong to a species of the dipteron genus Phora, which seems to be undescribed. From the hymenopterous cocoons appeared specimens of Pimpla annulipes Brullé.ł Some young spiclers from a similar nest were kindly identified by Mr. Nathan Banks as belonging to the genus Epeira.

So far as I can ascertain no other species of Phora is kuown to be parasitic on spiders eggs. Some species live upon dead insects or snals, others in rlecaying vegetable matter, while a few are intermal

\footnotetext{
*Contributions from the Zoological Laboratory of the University of Texas. No. 29 .

I Spiders' eggs seem to be the customary hosts of the various species of Pinfla. Howard, in an interesting paper on the hymenopterous parasites of spiders (Proc. Ent. Soc. of Washington, Vol. II, No. 3, P. zyo) mentions three other Americas species of Pimpla which infest the cocoons of Epeirid spiders.
}

parasites of other insects. There can be no doubt that the Phoras were primary parasites of the spiders eggs and not secondary ones living in the Pimpla larvae, as the Phoru larvae of all sizes were free, the smaller ones evidently failing to mature from lack of food, only two spider eggs remaining from the whole nestful. This is thus not a case of true parasitism accompanied by degeneration, but a condition where a predatory instinct and a considerable power defence must be possessed by the larva to enable it successfully to live and develop in the midst of a nest full of young spiclers, voracious often to camnibalism.

The following is the description of the new species of Phora.

\section{PHORA EPEIRAE, sp. nov.}

Length, 3-3.5 $\mathrm{mm}$. Rather broad and stout, almost wholly yellow. Abdomen quadrimaculate. Face shining, delicately punctulate, with a lateral row of four bristles: the vertex with four bristles, arranged at the

\footnotetext{
$\ddagger$ For a complete list of the European species with their food-habits see Hrauer, Systematisc he Studien der J JipternLarven. benkschriften der mathematisch-naturmissenschaftlichen Classe der k. Akademie der Wissenschaften Wien. 1id. 47 p. 66 . ${ }^{8} 88_{3}$.
} 
corners of a square, between the lateral rows; lower edge of the face at the middle with a row of four downwardly directed and smaller bristles. Antennae luteous, except the third segment of the arista which is black. Palpi yellow. Post ocular cilia stout, black, the lowest three or four which are below the eye being stout, and twice as long as the others. Thorax yellow, paler below and brownish above, except for a rather wide lighter dorsal vitta; with a few lateral biack hairs and two

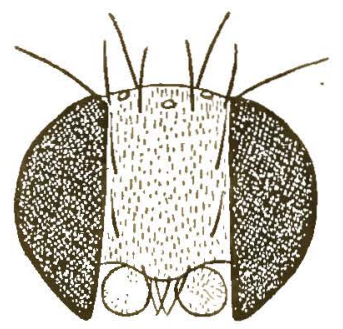

Phora epierae Brues. IIead, frontal view.

stout macrochaetae behind each wing. Scutellum with 2 marginal macrochaetae. Abdomen yellow; first and second segments each with a large quadrate, very sharply defined lateral black spot (that on the second absent in one specimen). 'The spots on the first segment each bear a tuft of small black bristles at the middle. Ovipositor black at extreme base. Legs yellow, each coxa with a few stout bristles at the apex, together forming a stiff backwardly directed brush. Femora wholly pale, the posterior ones deeper yellow. Tibiae, especially the posterior pair, spinulose above; four posterior tibiae with in single apical spur, that of the middle leg very long, half as long as the tibia. The posterior tibine have a fine black line abose, their tarsi bilineate with black externally. Wings light yellow, faintly dusky at the tips. Costal vein very much thickened on its basal half, its spines moderate: second longiturlinal vein bifurcate, the furcation and the tip of the costal vein forming the apex of a low isosceles triangle. Four equally distinct discal longitudinal veins.

Described from four female specimens, Austin, Tex.

This species may be readily distinguished from P. scalaris Loew, by the coloration, and from the European P. interrupta Ztt., by the spinulose hind tibiae. The maculation of the abdomen will distinguish it from any known North American species.

\section{NEOGLAPHYROPTERA OPIMA Lw. (?)}

Larva. Length $15 \mathrm{~mm}$., greatest width 1.30 mm. Body elongate, tapering at both ends; the constrictions between the body segments

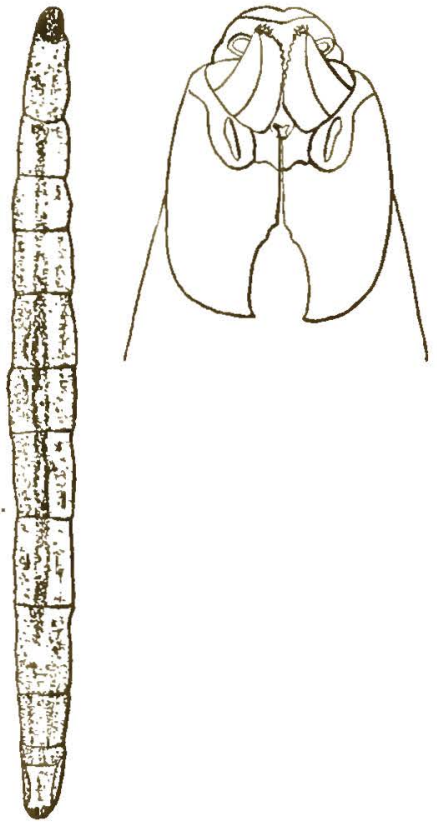

Neoglaphyroptera opima 1,W (?) Larva and head of larva, ventral view. 
not well matked. Color uniformly yellowish white, except where the internal organs produce a grayish tint owing to the transparency of the integument. llead black, shining, oblong, but little narrowed in front; about onc-half longer than wide. The posterior margin above is acutely emarginate. The occipital lines slightly convergent posteriorly, more strongly near their coalescence, which is at the angle of the posterior emargination. Antennae rudimentary, extending but little above the surface of the head; the carities at their bases large and distinct. Ocelli absent. Labrum prominent, the Heshy part emarginate in front ; the horny, basal part pectinate along the inne matgin, the teeth slender and curved. Handibles subtriangular, regularly serrate along the inner margin, otherwise without teeth or protuherances. Body smooth, entirely without hairs or spines. First thoracic segment nearly as long as the following, after which the segments increase in length, the anal one being equa! to the head and first thoracic segment together. Body much contracted in the anal segment, although the integument is not so sharply constricted. The rudiments of the compound eyes of the imago are distinctly seen as two dark oval discs near the surface of the dorsal sclerite of the first thoracic segment, directly above the imaginal dises of the first pair of legs.

Pupa. Length $7.5 \mathrm{~mm}$. Entire body nearly white with the stigmata black.

Several nearly grown larvae of this species were found under the bark of a fallen oak log. 'They soon pupated and one of them which was allowed to transform, emerged after a pupal stage of only fifty hours duration. The larvae spin a delicate web in which they lie suspended and move about under the bark. They are so extremely delicate that the web is necessary to prevent them from being dried up from contact with the dry bark. At times the larva moves its head towards the web and apparently eats the strands as it glides along. After pupation it lies half suspended in the web, which adheres to the integument wherever it touches.

\section{EUxesta NITIDIVENTRIS Lw.}

A very large number of fully grown larvae which proved to belong to this species were found beneath the bark of a dead pecan tree (Carya pecan) during the month of January. They were clus. tered together in groups of a hundred or more individuals, their bodies adhering together on account of their very sticky consistency, The greater number of the larvae were seen at a distance of five or six feet above the surface of the ground. Their habitat is like to that of one of the European Ortalinae, Psairoptera, which has been found under the bark of pine trees. (Zetterstedt, Diptera Scandinaviae, VI, p. 2265.)

Laria. Length $f^{-6} \mathrm{~mm}$. Body composed of eleven segments, narrow and somewhat pointed anteriorly, gradually enlarged posteriorly, the apex rounded. Mouth parts very retractile, the hooks separated. Head nearly as long as the first two thoracic segments togelher. Body segments without any distinct ambulatorial projections, the segments being only slightly produced ventrally at the margins. The anal segment bears two subdorsal papiliae on the sides of which the stigmata are situated.

The larval habits of this species are quite different from those of the closely related $\mathrm{E}$. notata, Wied. which was bred 
by Riley from larvae found in the pulp of an osage orange. The larva of an European genus of Ulidinae which has been described by Braner (loc. cit.), is quite similar to that of Euxesta.

The imagines which I bred do not agree very well with Loew's description of E. nitidizentris, yet seem undoubtedly

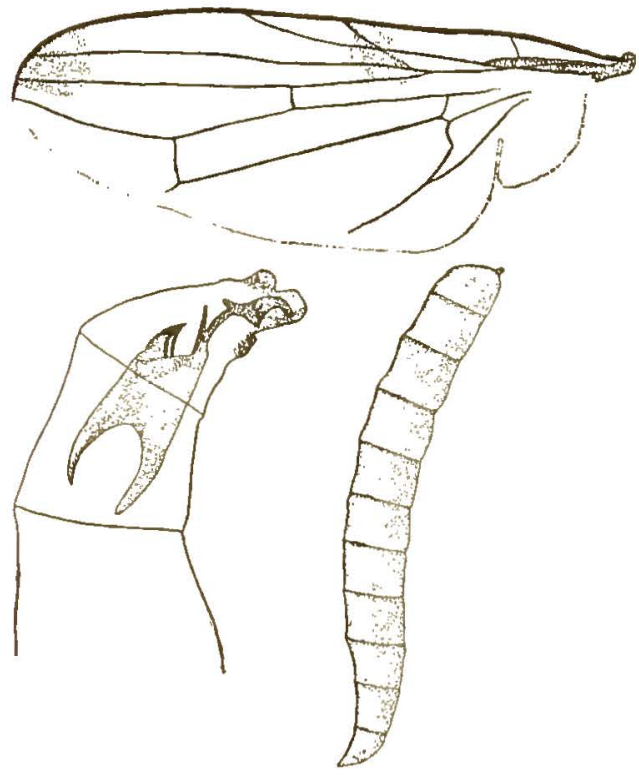

Euxesta nitidiventris Lw. Wing, larva and head of larva, showing mouth-parts.

to belong to the same species. I therefore append a description of both sexes in their fully mature state.

Male. Length $3.5-4 \mathrm{~mm}$., of wing $3.25-$ $3.50 \mathrm{~mm}$. Dark shining metallic blue, vertex blue, front brown. Antennae red brown, arista, dorsal and apical part of third joint blackened. Face at antennae with a white transverse pollinose stripe, blue below; cheeks white pollinose. Thorax and abdomen dark shining metallic blue. All the coxae brown, anterior and posterior ones slightly blackened. Interior legs black except basal two thirds of first tarsal joint. Niddle and posterior legs black, with knees yellow and tibiae brownish on inner side, first joint of tarsi also yellow. Wings hyaline, with an apical dark spot extending slightly beyond the third longitudinal rein, also a median spot at tip of auxiliary vein extending to a little beyond the third vein.

Female. Differs from Loew's description as folloys: femora metallic blue, often brownish tinged. Knees yellowish. tibiae brownish black, tarsi black except first joint.

Pseudopyrellia cornicina Fabr.

During the month of December, while collecting insects in cow dung, I unearthed several remarkable dipterous larvae of a brilliant blue color. On the evening of the same day they began rapidly to lose their brilliancy and pupated during the following night. After several weeks they emerged and proved to be specimens of the common Muscid fly, Pseudopyrellia cornicina Fabr. I am at a loss to account for such a bright color in this Muscid larva. living concealed from view during its entire life, as all or very nearly all other larva which feed upon cow dung are colorless or of a somber brownish color. 

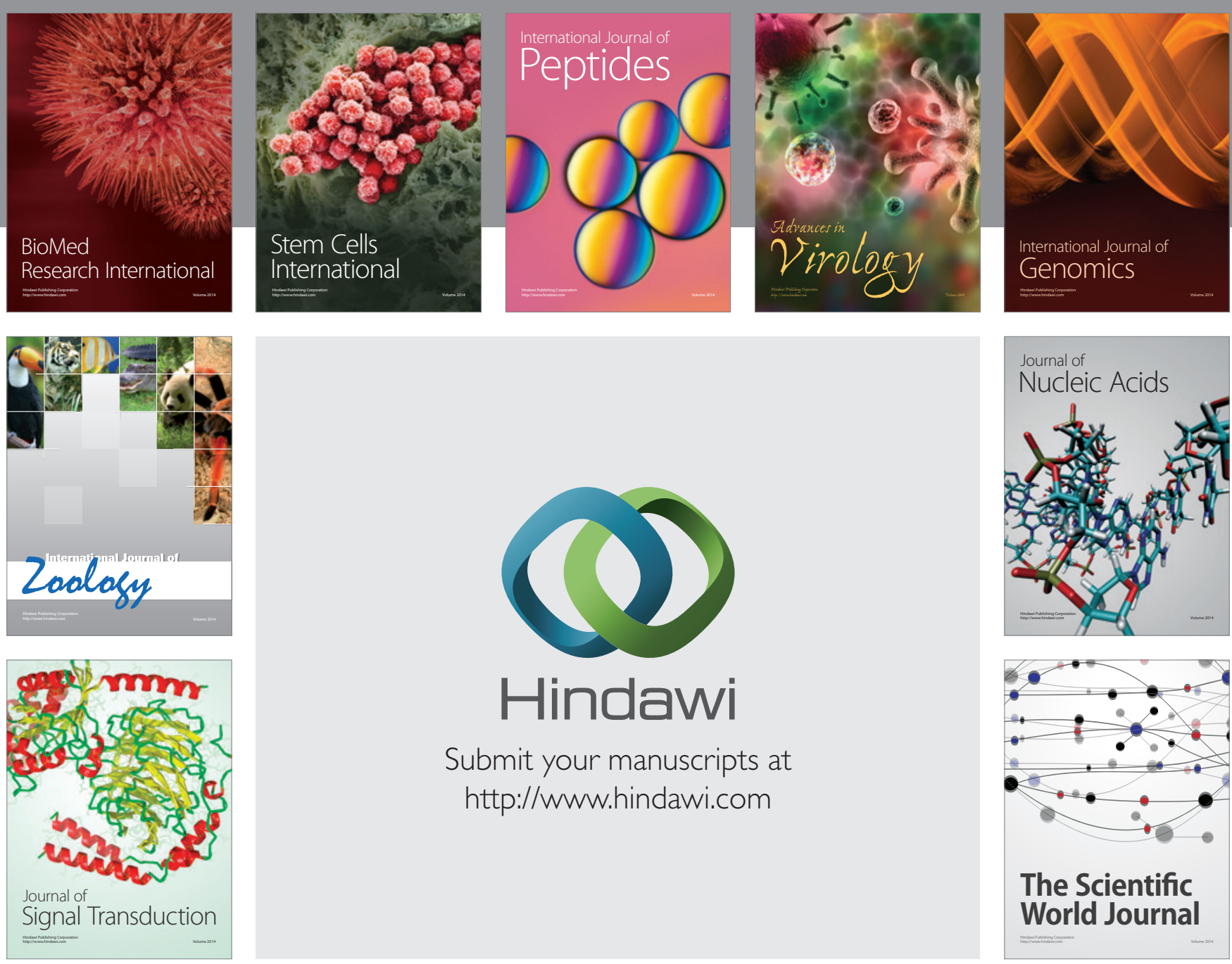

Submit your manuscripts at

http://www.hindawi.com
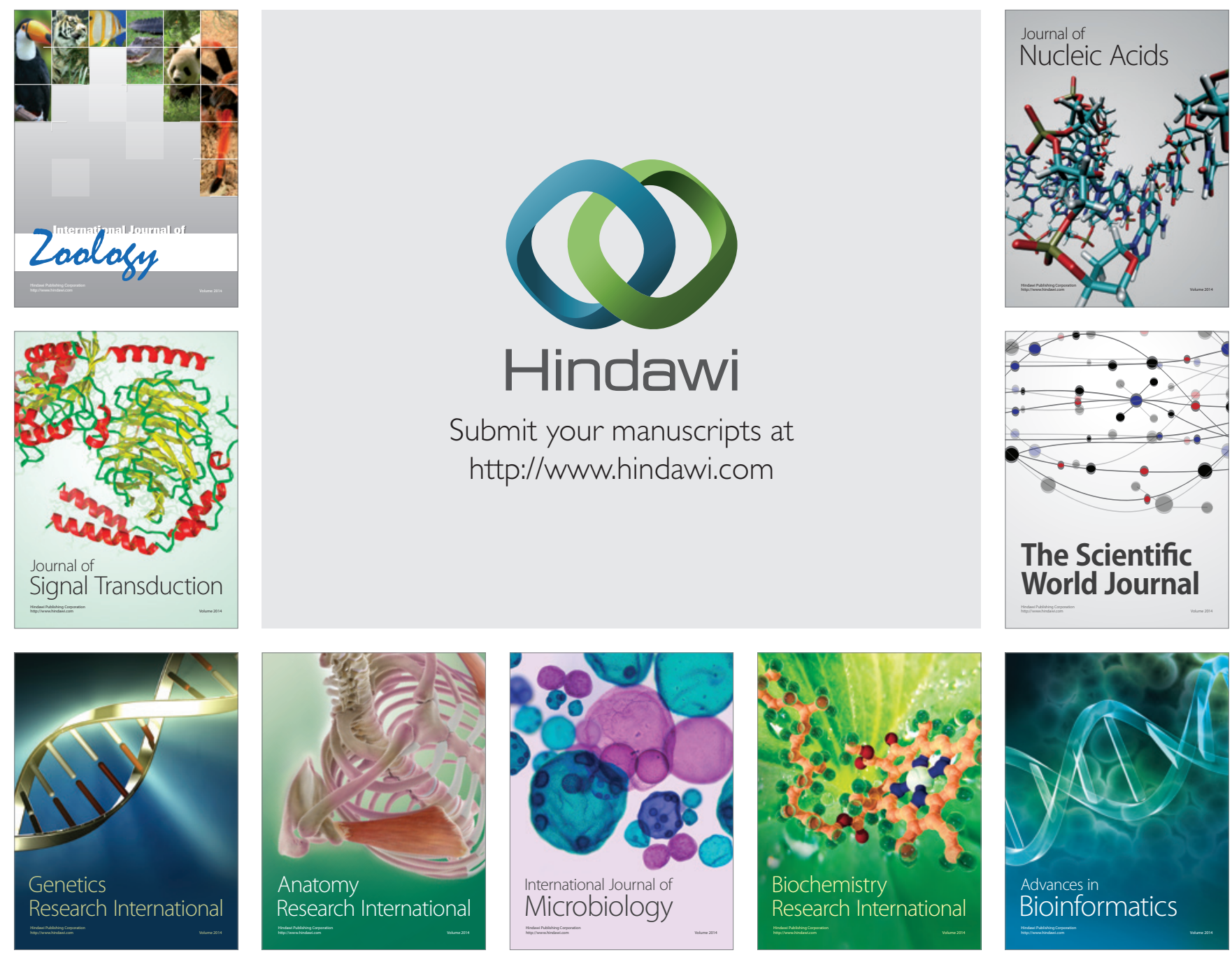

The Scientific World Journal
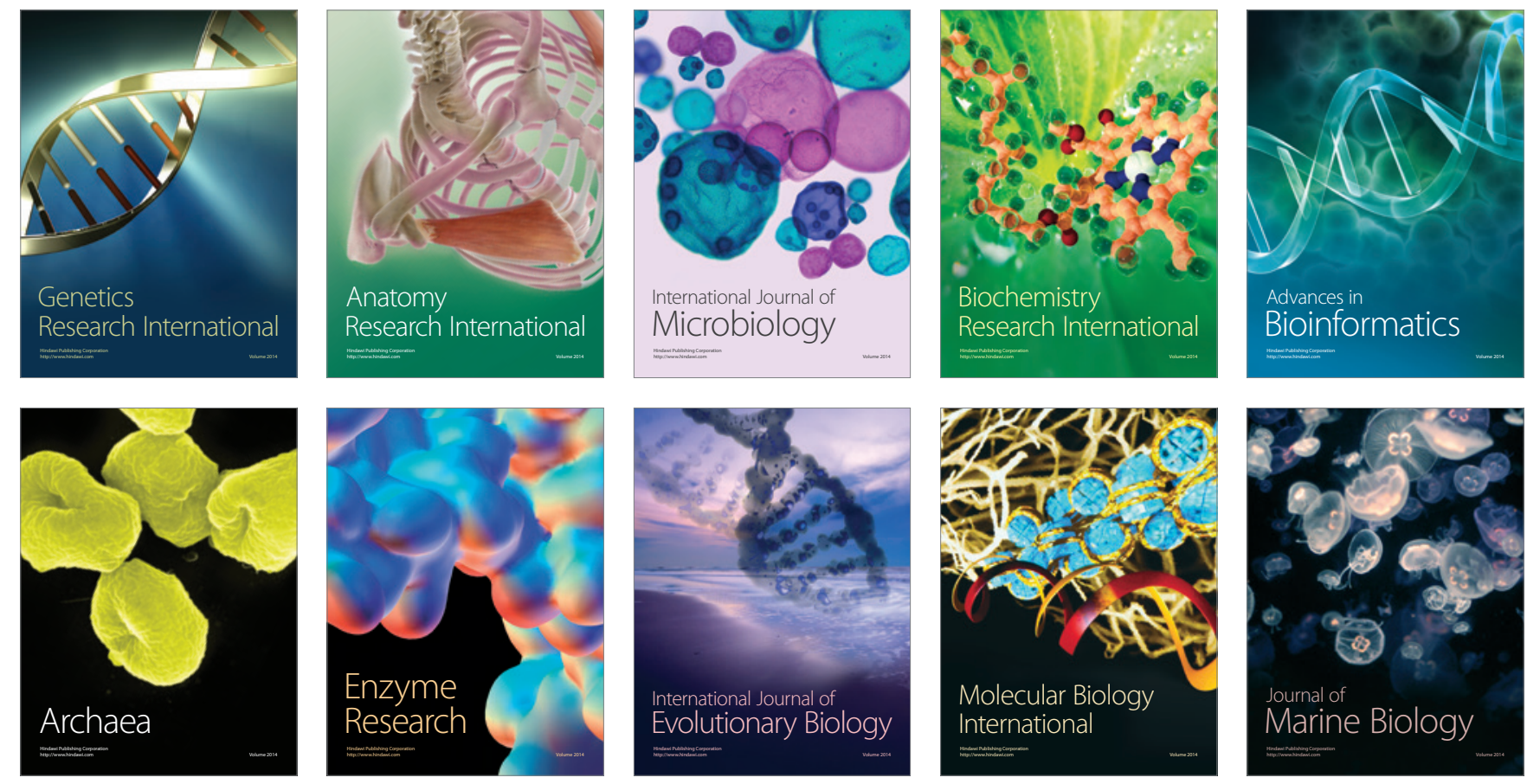